\title{
Challenging the Status Quo through Social Influence: Changes in Sustainable Consumption through the Influence of Social Networks
}

\author{
Iljana Schubert ${ }^{1, *}$, Judith I. M. de Groot ${ }^{2}$ and Adrian C. Newton ${ }^{3}$ \\ 1 Sustainability Research Group, Department of Social Sciences, University of Basel, 4051 Basel, Switzerland \\ 2 Faculty of Economics and Business, University of Groningen, 9747 AJ Groningen, The Netherlands; \\ j.i.m.de.groot@rug.nl \\ 3 Centre for Ecology, Environment and Sustainability, Faculty of Science and Technology, \\ Bournemouth University, Bournemouth BH12 5BB, UK; anewton@bournemouth.ac.uk \\ * Correspondence: iljana.schubert@unibas.ch
}

Citation: Schubert, I.; de Groot, J.I.M.; Newton, A.C. Challenging the Status Quo through Social Influence: Changes in Sustainable Consumption through the Influence of Social Networks. Sustainability 2021, 13, 5513. https://doi.org/10.3390/ su13105513

Academic Editor: Jose Ramon Saura

Received: 31 March 2021

Accepted: 9 May 2021

Published: 14 May 2021

Publisher's Note: MDPI stays neutral with regard to jurisdictional claims in published maps and institutional affiliations.

Copyright: (c) 2021 by the authors. Licensee MDPI, Basel, Switzerland. This article is an open access article distributed under the terms and conditions of the Creative Commons Attribution (CC BY) license (https:// creativecommons.org/licenses/by/ $4.0 /)$.

\begin{abstract}
This study examines the influence of social network members (versus strangers) on sustainable food consumption choices to investigate how social influence can challenge the status quo in unsustainable consumption practices. We hypothesized that changes to individual consumption practices could be achieved by revealing 'invisible' descriptive and injunctive social norms. We further hypothesized that it matters who reveals these norms, meaning that social network members expressing their norms will have a stronger influence on other's consumption choices than if these norms are expressed by strangers. We tested these hypotheses in a field experiment $(\mathrm{N}=134)$, where participants discussed previous sustainable food consumption (revealing descriptive norms) and its importance (revealing injunctive norms) with either a stranger or social network member. We measured actual sustainable food consumption through the extent to which participants chose organic over non-organic consumables during the debrief. Findings showed that revealed injunctive norms significantly influenced food consumption, more so than revealed descriptive norms. We also found that this influence was stronger for social network members compared to strangers. Implications and further research directions in relation to how social networks can be used to evoke sustainable social change are discussed.
\end{abstract}

Keywords: social networks; injunctive and descriptive norms; sustainable food consumption; social influence; sustainability

\section{Introduction}

Drastic changes in the way we consume energy and resources are needed for the survival of humans and other species, requiring a system-wide change in practices and uptake of low-carbon products and behavior [1]. The urgency of the climate change situation requires rapid changes in consumer behavior [2]. Recent environmental and political movements, such as 'Fridays for Future' or 'Black Lives Matter', have highlighted the strength of social influence to challenge the status quo, leading to serious discussions about climate change and racial discrimination and the re-evaluation of their governance. For example, one development arising from the 'Fridays for Future' movement is the 'flygskam' trend, or flight shaming, pointing out that flying is a shameful act in light of the climate change crisis, leading to a reduction of air travel, particularly in Sweden [3]. Thus, social influence, understood as the influence of peoples' social environment on their attitude, norms, and behavior, could bring about the much-needed drastic change in behavior (e.g., in relation to air travel) which would take longer to achieve through regulatory or market-based policies (e.g., slow process in air travel) [4]. Social influence can happen at many levels, and most movements such as 'Fridays for Future' or 'Black Lives Matter' $[5,6]$ start in niches and are often made up of many social networks $[7,8]$. 
Although social influence can be disruptive and challenge the status quo, the mechanisms of how this happens through social networks are still unclear. Different theoretical approaches and empirical evidence suggest that there are a number of ways in which a person's behavior can be changed through social influence. For instance, social learning theory [9] suggests that behavior is learned through observing and imitating others conduct. Further, social identity theory [10] and self-categorization theory [11] suggest that behavior is influenced through revealed social norms, discussed or shared in relevant social groups (i.e., social networks). These theories highlight the role of social norms, which can be observed or communicated in a different way. Social norms are informal rules that guide group behavior [12]. The role of social norms with regards to changing pro-environmental behavior is two-fold: Social norms mainly halt and slow down social change; however, they can also be used to inspire it [13].

Social norms are often split into descriptive and injunctive norms [14]. Descriptive norms refer to people's perceptions about what others do, whereas injunctive norms describe people's perceptions about what others (dis)approve of. A recent meta-analysis highlighted their relevance again, showing that making descriptive and injunctive norms salient indeed influences behavior [15]. In particular, research found that a combination of a descriptive norm message in favor of acting pro-environmentally together with an aligned injunctive norm message, suggesting that the majority of people also approve of this behavior, resulted in the highest increase in pro-environmental behavior $[14,16]$. Congruent injunctive and descriptive norms were also found to lead to higher pro-environmental intentions [17].

Often, however, descriptive and injunctive norms are not congruent in relation to most pro-environmental behaviors. That is, even if people are generally in favor of a proenvironmental behavior (injunctive norm, e.g., in relation to sustainable food consumption), they still do not perform that behavior (descriptive norm, e.g., purchasing sustainable food). In particular, research shows that in such cases, people are more likely to act on the salient descriptive norm, hereby making it less likely that they perform the pro-environmental behavior [14]. An example of this is short-distance air travel for holiday purposes (e.g., weekend city trips), which, prior to COVID-19 had become a popular activity among certain social groups (mainly young, well-educated, capital-city dwellers) [18]. Indeed, this example highlights the prevailing descriptive social norm regarding air travel in these groups. However, research has shown that in situations where people maintain or build social relationships, they are more likely to focus on injunctive norms, rather than descriptive ones $[19,20]$. Hence, in an intervention that actively reveals the injunctive norm in favor of pro-environmental behavior, in addition to a (likely mismatching) descriptive norm, we could still expect an increase in the desired environmental behavior (in line with the injunctive norm). However, the question is, are people equally influenced by all members in society, even in new situations?

Indeed, research into social influencers has shown that strangers can have an influence over topics ranging from what to eat [21] to policy preferences [22], although the strength of this influence relative to that of peers is still unclear. In general, people take on norms from their in-group members to increase similarities with peers and distinguish themselves from out-group members by rejecting their norms (social identity theory [10]; self-categorization theory [11]). Thus, it appears most likely that people would act according to revealed injunctive and descriptive in-group (social network) norms, rather than in line with those from the out-group (strangers). Hence, in this study we investigated the relative influence of revealed injunctive and descriptive norms of social network members vs. strangers on actual organic food consumption.

Current food production and consumption practices account for $30 \%$ of anthropogenic greenhouse gas (GHG) emission and up to $70 \%$ of human water consumption $[23,24]$. Food choices are to a large part driven by social factors $[25,26]$, thus making it the ideal area of research to understand how social influence could change behavior on a larger scale, with a possible substantial impact. So far there is no commonly agreed upon definition 
of what delineates sustainable food. However, certain aspects of sustainable food, such as organic and Fairtrade, are clearly defined. Hence, since defining what demarcates a sustainable diet is not straight forward [27], food which is ecological and Fairtrade was deemed sustainable for the context of this research. Within this category falls food which is organic, Fairtrade, locally produced, and food with reduced or no packaging.

Overall, research focusing on food consumption has found a strong correlation between people's food choices and that of their social network, with a closest match between spouses but also across peers for some food groups [26]. This research literature can be divided into several strands. The largest strand of research focusses on the influence of social networks on unhealthy food and drink consumption practices and related health issues; such as alcohol consumption [28], sugar intake [29], or obesity [30].

So far, only a small strand of literature examines the influence of social networks on sustainable food practices (cf. [31-33]). Most of these focus on explaining sustainable consumption choices with social network or peer effects, rather than the underlying mechanism of how social networks influence behavior. An exception is the study by Salazar et al. [33], who investigated the impact of normative information on sustainable food choices (chocolates). In their experiment, they compared three conditions: (1) A descriptive norm (how many peers had chosen a sustainable product), (2) a descriptive norm together with an injunctive norm (how many peers had chosen a sustainable product and approved of it) with (3) a control condition (no normative information). Salazar et al. found that in the normative conditions people were more likely to choose a sustainable product compared to the control group. Salazar et al.'s [33] findings thus support the idea of a direct link between descriptive and injunctive norm saliency and sustainable behavior. Interestingly, the study also found no difference between the two normative conditions, i.e., descriptive norm information vs. descriptive and injunctive norm information. Similar research, focusing on understanding and harnessing the influence of social networks (family and peers) on food consumption choices, can be found in the health domain. A number of these studies are field trials (e.g., on reducing sugar intake [29], meta-analysis on determinants of (un)healthy dietary practices [34]). However, none of the research we have found compares the influence of social network members to that of strangers. Neither have we found research showing how normative information could be revealed within networks in real life.

Scott's [35] research on discussions within networks provides a suggestion of how norms could be revealed (or 'made salient') in real life. The results showed that talking to network members about a certain topic can influence people's attitudes and in turn their norms in relation to this topic. Other studies have also shed some light on how social networks can be used to reveal social norms. For example, a study investigating the relationship of different social network factors with sustainable food consumption [36] showed that the larger the group of social network members a person talks to about food matters, the stronger an individual's descriptive norm to purchase sustainable food. Although the study by Schubert [36] did not collect data in respect to the nature of the food discussions between network members, these two studies imply that discussing a specific type of pro-environmental behavior within a social network will likely make salient (injunctive and descriptive) norms, hereby making it easier to act upon them. Therefore, the present study focused on discussing sustainable food matters as a real-life example of how to reveal the more visible descriptive and the less visible injunctive norms towards sustainable food choices.

Thus, the main aim of this experimental study was to examine if descriptive and injunctive norms, revealed through discussions in relation to sustainable food matters, led to more sustainable food consumption choices made by people paired-up with social network members than those paired with a stranger. In this study, we measured actual sustainable food consumption in relation to organic consumables, as this categorization is well known and easily distinguishable in shops. 
We put forward the following hypothesis:

Hypothesis 1 (H1). Individuals paired with a social network member will choose more organic (vs. non-organic consumables) compared to those paired with a stranger, after having revealed their injunctive and descriptive norms in favor of sustainable food consumption.

We made the following assumption: We expected that the expressed 'less visible' injunctive norm towards sustainable shopping (i.e., the importance of buying sustainable food shopping) was likely to be positive. The reason for this is that if there are no negative personal consequences involved in choosing a sustainable behavior, such as a higher price or less availability, then people are more likely to choose the more sustainable option as most people have values and norms in favor of doing good for the environment $[37,38]$. In this study, we measured sustainable food consumption and, thus, expected that the prevalent injunctive norm would be the desired behavior (i.e., to choose organic over nonorganic consumables on offer). The expressed descriptive norm in relation to sustainable food consumption is likely to vary, depending on whether individuals already purchase sustainable food (positive descriptive norm) or not (negative descriptive norm). However, as mentioned above, in social situations (maintaining or building relationships) people might be more likely to focus on injunctive norms $[19,20]$. Thus, it is likely that the revealed negative descriptive norm information, indicating that people do not tend to purchase sustainable food, would be overridden by a stronger (and overwhelmingly positive and made 'visible') injunctive norm in favor of sustainable food consumption.

Hence, we put forward the following hypothesis.

Hypothesis 2 (H2). The revealed injunctive norm influences sustainable consumption choices more than the revealed descriptive norm.

\section{Method}

The experiment was run as an activity for the Festival of Learning at Bournemouth University, UK. The Festival of Learning provided a good opportunity to investigate social influence as some individuals attend on their own (so they could be paired with a 'stranger') and some attend the festival with friends or family (so they could be paired with a social network member). The activity was advertised under the following title, 'What others tell us about our shopping behavior'. The following information was provided about the activity: 'Ever wanted to take part in psychology research? Now is your chance! Come and see our Psychology Department and have the opportunity to take part in a short experiment about your shopping behavior as an example of how and why we measure human behavior. You can also learn about the type of information collected and conclusions that can be drawn from such research.' Ethical approval for the experiment was sought from the University of Bournemouth Research Council prior to running both activities and collecting data.

The present study used a one-way between-subject design. The manipulation variable was the pairing of participants either with a social network member or a stranger to discuss food matters, in relation to current sustainable shopping behavior (revealing the descriptive norms) and the importance of sustainable food shopping (revealing the injunctive norms), during the pair-work activity. The participants did not receive any incentive other than consumables (i.e., cold or hot beverage and biscuits) for taking part in the experiment.

\subsection{Procedure}

Participants arrived at the psychology research lab either on their own, in pairs, or small groups. Upon arrival they were greeted by the researcher who explained the experiment. Before the start of the activity, participants were informed that they were free to leave at any time and written consent was sought from each participant, in order to use the data. 


\subsubsection{Dividing Participants into Pairs for the Experiment}

At the start of the experiment, participants were either paired with a stranger or with a member of their social network (friend, family member, or other person they arrived with). The pairing up of participants was based on opportunity sampling. Sampling occurred in three ways: (1) When people arrived with one other social network member they were mainly kept together; (2) when two people arrived that did not know each other (strangers) they were paired together; (3) if two groups of people arrived, they were sometimes split into pairs of strangers. Sampling occurred in this way to balance out stranger and social network group samples.

\subsubsection{The Experiment}

All participant pairs were then taken to separate cubicles to work through the experiment questionnaire (Figure A1, Appendix A). The experiment consisted of three parts (Appendix A, part 2). In the first part of the experiment, participants were asked to independently fill in one question about their current sustainable food shopping behavior. This was followed by two questions they were asked to discuss with their assigned partner. In the discussion questions the partners were asked to discuss their current sustainable food shopping behavior (revealed descriptive norm) and the perceived importance of purchasing sustainable food (revealed injunctive norm). Participants were asked to record their answers to the two discussion questions, writing down similarities and differences in their shopping behaviors and their expressed importance of sustainable food shopping. After the discussion, they were asked to independently fill in some further questions. These asked their intention to purchase sustainable food in the future which was used as a decoy dependent variable and was not analyzed. Additionally, they were asked about the size of their social network (degree) and the percentage of sustainable shoppers in the network. Furthermore, participants were asked about the lengths of the relationship and the nature of the relationship (friend, family, stranger, etc.) with their discussion partner. This information was only used to verify the relationship between network partners and strangers and not included in the analysis because it was only relevant for network members. The last two questions collected basic demographic information, namely age and biological sex.

Once participants had completed the experiment questionnaire the pairs were asked to join the researcher for a debrief, where the participants were offered the consumables (the dependent variable). It was not revealed to the participants that their consumption choices were part of the experiment until after they had made their choices. The consumables were on offer in a separate room (Figures A2 and A3, Appendix A), which was about $2.5 \times 3.5 \mathrm{~m}$ large and was only accessed after the pair-work. Participants entered the room with their paired-up partner, thus their social network member or stranger, and were left to make their own choices before re-joining the researcher. The organic and non-organic options were set up on separate tables, one in a more obvious and easily reachable position on the left side of the room and the second positioned on the right side of the room, in a slightly less visible and less reachable position (Figures A2 and A3, Appendix A). Beverage containers (plastic cups, cardboard cups, ceramic cups, and glasses) were placed on the table next to the easily reachable consumables. The set-up of the organic and non-organic consumables was regularly reversed during the day and over the period of the data collection so that at different times of the day either organic or non-organic items were placed in the easily reachable and visible position. This reversed placing was done to exclude a location bias so that the choice of consumables was not based on their position in the room but due to actual preferences (cf. [38,39]).

During the debrief participants were asked a manipulation check question to test whether they were blind to the actual behavior measure of the study, their actual consumption choices (Figure A4, Appendix A). At the end of the debrief participants were thanked for their participation and escorted out. 


\subsection{Dependent and Independent Variables}

\subsubsection{Dependent Variable}

Actual consumption choices. We measured actual food consumption choices. On offer were the following consumables: tea (black and peppermint), coffee, water, orange juice, milk, sugar, and biscuits. All choices were offered as organic and non-organic and were matched in appearance.

To match their appearance consumable items were decanted into identical containers such as glass Kilner jars (i.e., for teas and coffees), glass jugs (i.e., for orange juice and water), bowls (i.e., for sugar), small milk jugs (i.e., for milk) and plates (i.e., for the biscuits). The only visible differences between the consumption choices on offer were the labels for each consumable item (e.g., organic tea vs. tea (for the non-organic consumable) which were written on same-sized labels in the same font. The labels were placed in front of the consumable items to avoid participants choosing items based on any visible differences between them. Additionally, participants had the choice of the following beverage containers: plastic cups, cardboard cups, ceramic cups, and glasses. These were not included in the actual consumption choice score. Actual consumption choices were recorded twice, once covertly by the researcher, while participants made their choice and a second time, by the participant, during the debrief. The double recording was done to avoid missing and incorrect data that might occur owing to social desirability recording of data on behalf of the participants [40] and human error in recording on both the participants and researchers' side. The actual consumption score was created by subtracting the sum of all the organic consumable choices from the sum of all the non-organic consumable choices made by each participant with possible answers ranging from -5 to 5 .

\subsubsection{Independent Variables}

Pairing with network member (manipulation variable). Participants were either paired with somebody they knew (i.e., social network member) or with a stranger to complete the experiment. This was a binary variable $(0=$ stranger, $1=$ network member $)$.

Revealed sustainable descriptive norms. The paired-up experiment partners were asked to discuss the following question 'How regularly do you buy sustainable food products that can be described by the categories above (i.e., fair-trade, organic, little or no packaging and locally sourced food)?' They were then asked to record similarities and differences that were discussed with the partners. These qualitative answers were coded in a dichotomous variable, with 1 (=positive descriptive norm towards sustainable food shopping) for individuals which indicated that they purchased some sustainable food at least some of the times, and 0 (=negative/non-positive descriptive norm towards sustainable food shopping). Unclear answers were cross-checked with the current sustainable shopping behavior'How often do you buy any of the following', answer options: Organic/Fairtrade/locally sourced/food with little or no packaging, measured on a 7-point semantic Likert scale ranging from never to always [36]. The current sustainable shopping behavior question formed the basis for the discussion and was not further analyzed. All answers were independently coded by two authors and difficult cases were discussed.

Revealed sustainable injunctive norms. Partners discussed the following question: 'How important do you think it is to buy sustainable food and why?'. Participants were again asked to record their discussed similarities and differences and these qualitative answers were also coded in a dichotomous variable. Answers were coded by two authors and cross-checked: 1 (=positive injunctive norm) was given to individuals who recorded that they found sustainable food purchasing important; 0 (=negative/non-positive injunctive norm) was given to individuals who reported that they did not find sustainable food purchasing important or recorded an answer which did not provide a value in relation to importance.

Size of the social network (degree). Network size was included as a confounding variable because research found that network size appears to influence norms and behavior. The direction of this influence is still unclear, with some studies reporting that larger networks 
are more likely to influence behavior (cf. [41]); however, other research suggests network size is negatively related to uptake of norms or adoption likelihood $[35,42]$. In this study we measured network size by asking participants: 'How large is your social network of friends, family, and important others? Please tick one of the options below: 1-5, 6-10, 11-15, 16-20, 21-25, 26-30, >30 (people) (size categories given by the researcher)' (based on Kadushin [43]).

Percentage of sustainable shoppers. The percentage of sustainable shoppers in one's network was also included as a confounding variable as it has been previously found to influence norms and in turn behavior [35]. In this study we asked participants to estimate the percentage of sustainable shoppers in their social network on a scale from $0-100 \%$. Participants were asked: 'How large is the percentage of people that buy sustainable food products in your social network? Please use the slider bar below to indicate the percentage of people that buy sustainable food products in your social network by marking your answer with an $X$ in the appropriate position. Below are some guidelines: $\leq 25 \%$ indicating a minority (about $1 / 4$ or less), $\approx 50 \%$ (more or less half of the people), $\geq 75 \%$ indicating a majority (more than $3 / 4$ of the people).' The slider bar was divided into steps of $10 \%$ from 0-100\%. This was based on a measure in Kadushin [43].

Experiment manipulation check. To test whether participants guessed that the consumables were part of the experimental set-up, all participants were asked the following question once they had chosen their consumables: 'What do you think the experiment was about?' This was an open-ended question.

\subsection{Participants}

Participants included people from the local community and university who were interested in attending the various activities organized during the Festival of Learning. The total sample included 176 participants; however, 6 participants were excluded because they did not pass the manipulation test by guessing that the consumables they chose were part of the experiment. A further 22 participants did not want any consumables and had to be excluded from the experiment. In addition, 10 participants did not record any revealed injunctive or descriptive norms, and thus did not follow instructions and had to be excluded from the experiment. An additional 6 participants had missing information in the confounding factors and thus were also excluded from the analysis, leaving a final sample of 132 participants for the analyses. This participant sample consisted of 72 participants in the social network members group and 60 in the strangers group.

\subsection{Analysis}

Analyses of the experiment results were performed in SPSS 26. We first performed a $t$-test and chi-square tests to establish whether our experimental set-up produced nonbiased results regarding the pairing of experiment partners and the placing of food items. Second, we performed a multiple linear regression to test whether our manipulation, namely the pairing of social network members and strangers, and the intervention, i.e., the discussion of current sustainable food shopping behavior (revealing descriptive norms) and the importance of sustainable food (revealing injunctive norms), resulted in significantly higher actual sustainable consumption for the social network members (H1). Furthermore, the regression analysis tested our second hypothesis, whether the revealed injunctive norms influenced sustainable consumption choices more than the revealed descriptive norms (H2). Finally, we regressed three independent variables (pairing, descriptive, and injunctive norms) and two confounding variables (number of social network members; percentage of sustainable shoppers in the network) on our dependent variable (actual consumption). 


\section{Results}

\subsection{Descriptive Results}

Table 1 provides descriptive information on the dependent, independent, and confounding variables included in the regression. Additionally, it provides descriptive information on current sustainable food shopping behavior, age, and biological sex.

Overall, we can see some variations in current sustainable shopping behavior in both groups (i.e., social network members and strangers), with scores varying between 2 (almost never) to 5 (often) in the social network group and from 1 (never) to 6 (almost always) in the strangers group (total range 1-7). However, both groups showed on average similar, relatively low, current sustainable behavior (i.e., sometimes). Independent sample $t$-test results confirmed that there were no significant differences between the pairs of strangers $(\mathrm{M}=3.93, \mathrm{SD}=0.89)$ and social network members $(\mathrm{M}=3.82, \mathrm{SD}=0.67)$ on current sustainable shopping behavior $\left(\mathrm{t}_{\text {current shopping }}(130)=0.81, p=0.417\right)$. The $t$-test results also confirmed that there was no significant difference in age between the groups $\left(t_{\text {age }}(129)=1.59, p=0.113\right)$. Furthermore, an independent sample $t$-test showed that there was also no significant difference in actual consumption related to the set-up locations of consumables in the room, (i.e., non-organic front $(\mathrm{N}=70, \mathrm{M}=0.41, \mathrm{SD}=2.24)$ and the organic front $\mathrm{N}=62,(\mathrm{M}=1.07, \mathrm{SD}=1.98, \mathrm{t}=-176, p=0.08)$. Therefore, the results of both set-up conditions were combined for the analyses. Finally, the chi-square test results showed no significant group differences based on biological sex with both groups having a slightly higher female population than males (social network members: females $=58.3 \%$, males $=41.7 \%$; strangers: females $=66.7 \%$, males $=33.3 \%)\left(X^{2}(1, N=132)=0.97, p=0.326\right)$. Thus, we concluded that the sampling procedure did not cause any bias regarding the consumable set-up, participant's current sustainable shopping behavior, or biological sex.

Table 1. Descriptive information of dependent, independent, confounding variables, and variables of interest according to experimental group (social network members vs. strangers).

\begin{tabular}{|c|c|c|c|c|c|c|c|c|c|c|}
\hline \multirow{2}{*}{ Variables } & \multicolumn{5}{|c|}{ Social Network Members } & \multicolumn{5}{|c|}{ Strangers } \\
\hline & Min & Max & Mean & SE & SD & Min & Max & Mean & SE & SD \\
\hline \multicolumn{11}{|l|}{ Variables in the multiple linear regression } \\
\hline Actual sustainable consumption $1, \mathrm{a}$ & -5 & 5 & 1.21 & 0.24 & 2.05 & -5 & 5 & 0.13 & 0.27 & 2.12 \\
\hline Revealed sustainable descriptive norms $2, b$ & 0 & 1 & 0.93 & 0.03 & 0.26 & 0 & 1 & 0.83 & 0.05 & 0.38 \\
\hline Revealed sustainable injunctive norms $2, \mathrm{~b}$ & 0 & 1 & 0.94 & 0.03 & 0.23 & 0 & 1 & 0.82 & 0.05 & 0.39 \\
\hline $\begin{array}{c}\text { Percentage of sustainable shoppers in the } \\
\text { social network }{ }^{3, \mathrm{c}}\end{array}$ & 6 & 65 & 33.50 & 1.91 & 16.22 & 4 & 78 & 37.35 & 2.13 & 16.51 \\
\hline Number of social network members ${ }^{3, \mathrm{~d}}$ & 3 & 33 & 18.28 & 1.01 & 8.59 & 3 & 33 & 16.67 & 1.16 & 8.97 \\
\hline Descriptive information only & & & & & & & & & & \\
\hline Current sustainable shopping behavior $\mathrm{e}$ & 2 & 5 & 3.82 & 0.08 & 0.67 & 1 & 6 & 3.93 & 0.11 & 0.89 \\
\hline Age $\left(\mathrm{N}_{\text {Strangers }}=59\right)^{\mathrm{f}}$ & 18 & 85 & 38.25 & 1.93 & 16.40 & 20 & 80 & 42.85 & 2.14 & 16.44 \\
\hline Biological sex ${ }^{b}$ & \multicolumn{5}{|c|}{$\begin{array}{l}\text { Females }=58.3 \% \\
\text { Males }=41.7 \%\end{array}$} & \multicolumn{5}{|c|}{$\begin{array}{c}\text { Females }=66.7 \% \\
\text { Males }=33.3 \%\end{array}$} \\
\hline
\end{tabular}

$\mathrm{N}_{\text {Strangers }}=60\left(\mathrm{~N}_{\text {Strangers age }}=59\right), \mathrm{N}_{\text {Social Network }}=72,{ }^{1}$ dependent variable; ${ }^{2}$ independent variable; ${ }^{3}$ confounding factor; ${ }^{\mathrm{a}}$ difference between sustainable and non-sustainable food choices, possible answers range -5 to 5 ; ${ }^{b}$ dichotomous variable (no $=0$, yes $=1$; male $=0$, female $=1) ;{ }^{\mathrm{c}}$ variable measured ranging from $0-100 \%$; ${ }^{\mathrm{d}}$ variable measured in size categories (e.g., $\left.1-5,6-10\right) ;{ }^{\mathrm{e}}$ variable measured on a 7 -point Likert scale; ${ }^{\mathrm{f}}$ variable measured as an open-ended number entry in years.

\subsection{Predicting Actual Sustainable Consumption}

The multiple linear regression results (Table 2) supported our hypotheses, showing that discussing descriptive and injunctive norms with social network members (compared to strangers) significantly influenced actual organic consumption choices (H1), leading to more organic consumption choices. In addition, we found that revealed sustainable injunctive norms (thus positive injunctive norms towards sustainable food) significantly influenced actual organic consumption choices (also Figure 1), thus providing support 
for hypothesis $\mathrm{H} 2$, showing a positive relationship. The revealed descriptive norms did not influence actual consumption choices. Additionally, the confounding factors (percentage of sustainable shoppers, number of social network members) did not explain actual consumption choices.

Table 2. Multiple linear regression of social network pairing (vs. strangers), injunctive and descriptive norms, and confounding social network factors on actual consumption choices.

\begin{tabular}{|c|c|c|c|c|c|}
\hline Variables & B & SE & $\beta$ & $\mathbf{t}$ & $\begin{array}{c}p- \\
\text { Value }\end{array}$ \\
\hline Pairing with social network member (vs. stranger) ${ }^{a}$ & 0.90 & 0.37 & 0.21 & 2.41 & 0.017 \\
\hline Revealed sustainable descriptive norms a & 0.47 & 0.60 & 0.07 & 0.79 & 0.433 \\
\hline Revealed sustainable injunctive norms ${ }^{\text {a }}$ & 1.21 & 0.59 & 0.18 & 2.06 & 0.042 \\
\hline Percentage of sustainable shoppers in the social network ${ }^{b}$ & 0.01 & 0.01 & 0.09 & 0.99 & 0.324 \\
\hline Number of social network members ${ }^{\mathrm{c}}$ & 0.01 & 0.02 & 0.04 & 0.52 & 0.603 \\
\hline (Constant) & -1.86 & 0.85 & & -2.20 & 0.030 \\
\hline
\end{tabular}

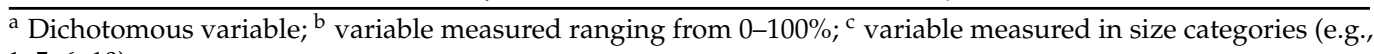
$1-5,6-10)$.

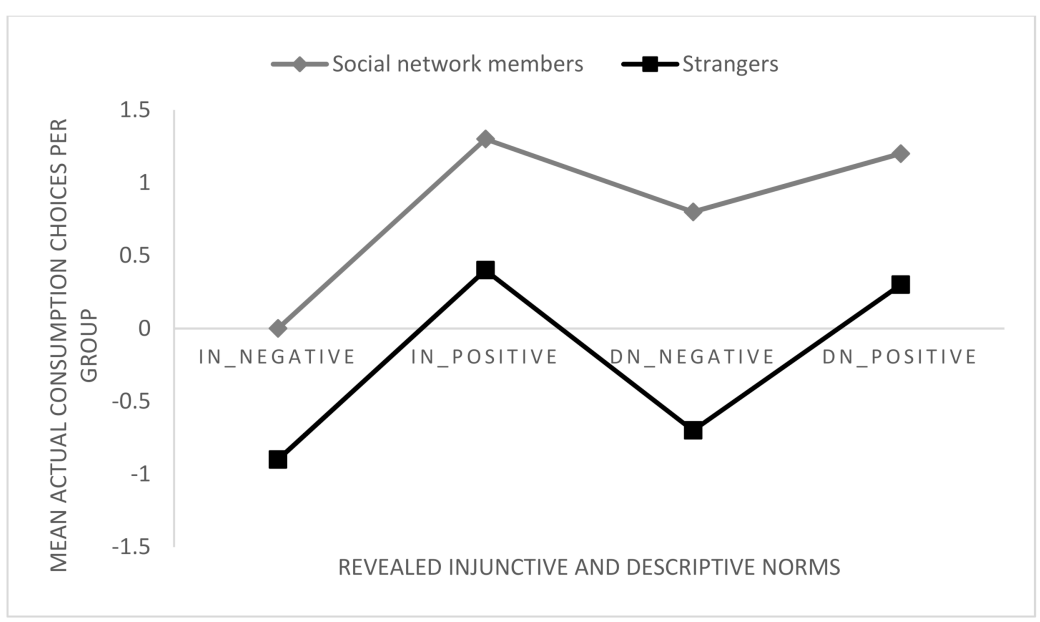

Figure 1. Actual consumption choices plotted against positive and negative (sustainable) injunctive and descriptive norms per experimental group (paired with a social network member or stranger). Note: Actual consumption choices ranged from -5 (all non-organic consumption choices) to 5 (all organic consumption choices, $0=$ equal amount of organic and non-organic choices), IN_negative = revealed injunctive norms not in favor of sustainable food, IN_positive = revealed injunctive norms in favor of sustainable food, DN_negative = revealed descriptive norms not in favor of sustainable food, DN_positive = revealed descriptive norms in favor of sustainable food.

\section{Discussion}

The overall aim of this research was to understand the mechanisms of social influence by looking at the influence of social networks on consumer behavior. Social networks form the building blocks of social movements and indeed society. Thus, to achieve dramatic changes we need to understand the role social networks play in changing behavior. Previous empirical research suggested that one plausible route could be via the communication of descriptive norms and injunctive norms (cf. meta-analysis by Bergquist et al. [15]).

Thus, in this experimental study we investigated the influence of revealed descriptive and injunctive norms through discussions on a particular topic (i.e., sustainable food). In particular, we explored whether descriptive and injunctive norms revealed by social network members had a stronger influence on actual consumption choices than those revealed by strangers. Both groups (strangers and social network members) showed similar initial scores of relatively low current sustainable behavior (i.e., sometimes) and reported social networks that varied similarly in size and sustainable shopping members. 
Nevertheless, the organic food consumption displayed varies significantly between the groups suggesting that social influence occurred most strongly through the social network. Specifically, we found that, in line with our hypothesis (H1), descriptive and injunctive norms revealed by social network members had a stronger influence on actual consumption behavior than those revealed by strangers. These findings are in line with social identity theory [10] and self-categorization theory [11], which suggest that people behave in line with in-group norms (i.e., those of the social network member) but try to distinguish themselves from out-group norms (i.e., those from the strangers). It is possible that this drive to distinguish oneself from the out-group also had an influence, resulting in strangers opting for the opposite choice and maybe also the opposite location, to each other. This would then suggest that norms could have a push or pull characteristic, depending on who reveals them.

Findings further showed that revealed injunctive norms in favor of sustainable food significantly influenced actual organic food choices, meaning that people were more likely to act in accordance with the revealed injunctive norms than the descriptive norms. This finding is in line with Cialdini and Trost [19] and Jacobson et al. [20], showing that if sustainable injunctive norms are made salient with social network members, to maintain or build relationships, they can override less sustainable descriptive norms. Of course, the experimental situation created was unique in that negative consequences were removed from the sustainable consumption situation (i.e., no increased cost or inconvenience). This may have made people feel able to choose more sustainable options as most people believe it is the 'right thing to do' (cf. $[37,38]$ ). Future research should validate these findings by repeating this experiment under more realistic conditions to investigate if the social influence of network members is strong enough to overcome negative consequences or barriers naturally inherent in sustainable consumption situations, such as increased cost [39] or food shopping habits [40-42]. This leads us to speculate that if, for example, subsidies were paid towards producing sustainable food, or non-sustainable food prices were adjusted to the real cost of their production, making sustainable food prices equal to that of non-sustainable food products, people would be very likely to purchase sustainable food [43].

It might be possible that, in addition to a salient injunctive norm influencing behavior, the revealed situational descriptive norms (i.e., watching your network member) might be responsible for the difference in actual consumption choices. In other words, it might be possible that observing a social network member choosing sustainable consumption choices (i.e., observing a situation-based descriptive norm) might have led to an increase of this behavior in the group. Indeed, some research has suggested that people are more likely to learn descriptive norms experientially (i.e., observing others) rather than conceptually (i.e., based on what others say they do) as shown in a cross-sectional study on community engagement [44]. A limitation of our study is that we were unable to separate discussion members when they made their choices so as to not arouse suspicion about the actual behavior measure. Therefore, we cannot separate whether experiential learning was more relevant than conceptual learning about norms. Future studies could investigate whether the focus should lie on experiential learning (i.e., observing others perform the behavior) or conceptual learning (i.e., hearing about others behavior) about norms or both.

Nevertheless, it seemed surprisingly easy to influence people's sustainable consumption behavior despite the relatively low current sustainable food consumption behavior reported (i.e., sometimes). Therefore, it might be possible to develop social marketing strategies and interventions which could harness the power of social networks in situations where new majority norms need to be made salient, or where a more visible majority descriptive norm towards the undesired behavior needs to be overridden by the less visible but likely more positive majority injunctive norm towards the desired alternative. An example of how to implement such a program comes from a feasibility study in the health domain. Gudzune et al. [29] successfully implemented a six-week program to decrease sugar intake among public housing residents, utilizing peer educators and social network 
helpers. Findings showed a significant decrease in sugar intake in peer educators and their networks. However, due to the peer educator aspect, the program was also a lot more complex and time-consuming than our study. Naturally, questions remain regarding the stability of our and Gudzune et al.'s behavior change effect and whether a more stable habit could be established with repeated exposure.

Furthermore, we controlled for two confounding factors, the percentage of sustainable shoppers in people's social networks and overall social network size, both previously found to influence consumer behavior [36,45]. We found that neither factor explained actual consumption choices. From these findings, it appears that there is no need for a majority to change consumer behavior, but that people can be influenced (at least in the moment) by single social network members. However, it is important to keep in mind that unlike the descriptive and injunctive norms, which were made salient through the discussion with a social network member, the other two social network factors were not made salient in this experiment. The question remains though: If the discussion topic had focused on the number of sustainable shoppers in the network rather than current shopping behavior and its importance, would people still have been influenced? Future research could try to disentangle whether there is a difference between the kind of information (i.e., whether to focus on personal, group, or societal social norms) that is most relevant in bringing about the biggest change in behavior in the desired direction.

Finally, we would like to point out a further possible limitation of our study. Although the sample of the study was varied, it was nevertheless a particular cohort of individuals that enjoyed learning new things and was open to new experiences. Since this applied to both groups, strangers, and social network members, and both groups were matched on key demographic and pre-experimental variables, we feel confident that the particular cohort had no significant impact on the results of this study.

The findings from this research, if replicated in even more natural settings, could suggest new routes into changing consumer behavior. The current study seems to suggest that for others to change their consumer behavior, no majority of already established sustainable consumers is needed. In particular, discussions with social network members might be strong enough to turn consumer behavior towards more sustainable choices, regardless of the initial situation, as they can make explicit and salient favorable norms in relation to sustainable behavior. In particular, because injunctive norms towards proenvironmental behavior are often positive but less visible, discussing such norms explicitly might help people to act on injunctive norms (e.g., your friend is in favor of buying sustainable products) rather than, for example, negative descriptive norms that can be perceived without such discussions (i.e., most people do not buy sustainable products in shops). Wider implications might be that new norms could be spread through social networks by making relevant (pro-environmental) behavior more visible, by talking about and demonstrating the desired behavior, in turn leading to behavior change. This finding is supported by the 'flygskam' trend, which discourages air travel and has been shown to lead to a drop in air travel, at least in the short-term. Thus, in order to spread the uptake of new behavior, different networks which are interlinked in social movements such as 'Fridays for Future' could simultaneously adopt strategies to reveal social norms, leading to a change revolution.

Author Contributions: Conceptualization, I.S. and J.I.M.d.G.; methodology, I.S.; formal analysis, I.S.; investigation, I.S.; writing — original draft preparation, I.S.; writing—-review and editing, I.S., J.I.M.d.G. and A.C.N.; supervision, J.I.M.d.G. and A.C.N. All authors have read and agreed to the published version of the manuscript.

Funding: The first author was in receipt of a Bournemouth University Studentship. The research was further funded through available funds for the Bournemouth University Festival of Learning.

Institutional Review Board Statement: The study was conducted according to the guidelines of the Declaration of Helsinki, and approved by the Ethics Committee at Bournemouth University, Faculty of Science and Technology in May 2014. 
Informed Consent Statement: Written informed consent was obtained from all subjects prior to the involvement in the study.

Data Availability Statement: The data that support the findings of this study are available from the corresponding author, I.S., upon reasonable request.

Conflicts of Interest: The authors declare no conflict of interest.

\section{Appendix A}

Part 1: Photos of the experiment set up

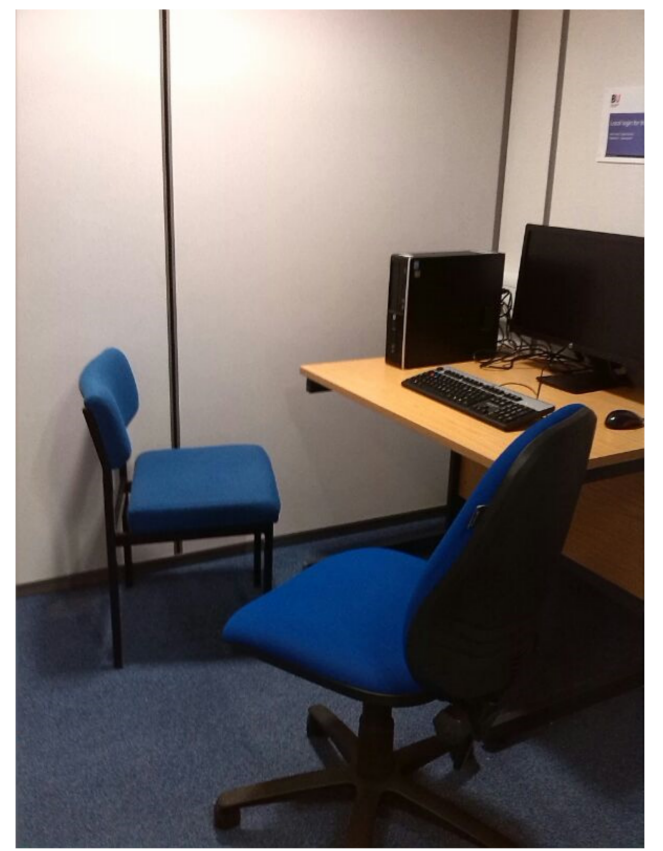

Figure A1. One of the rooms for the pair activity.

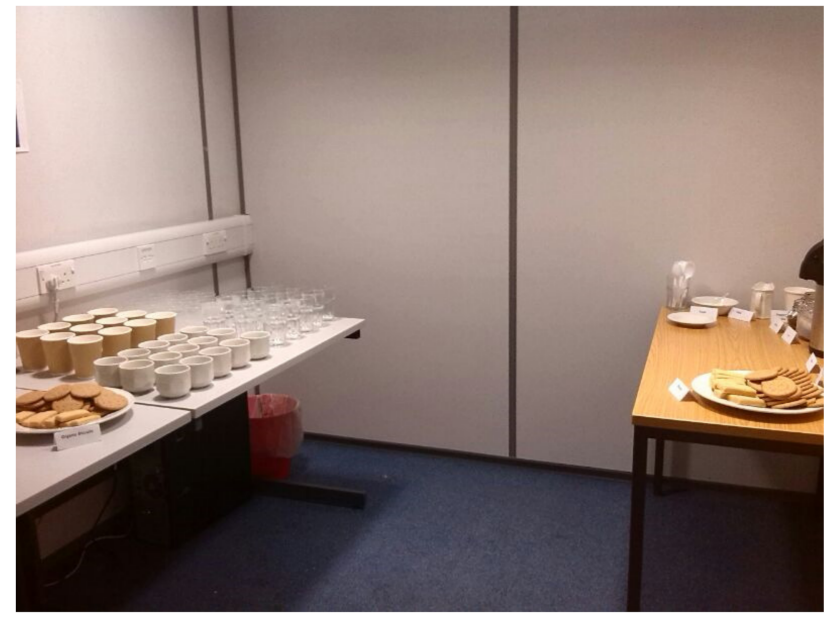

Figure A2. View into the room with the consumables. Left table shows organic consumables. Right table shows non-organic consumables currently in the less convenient position. 


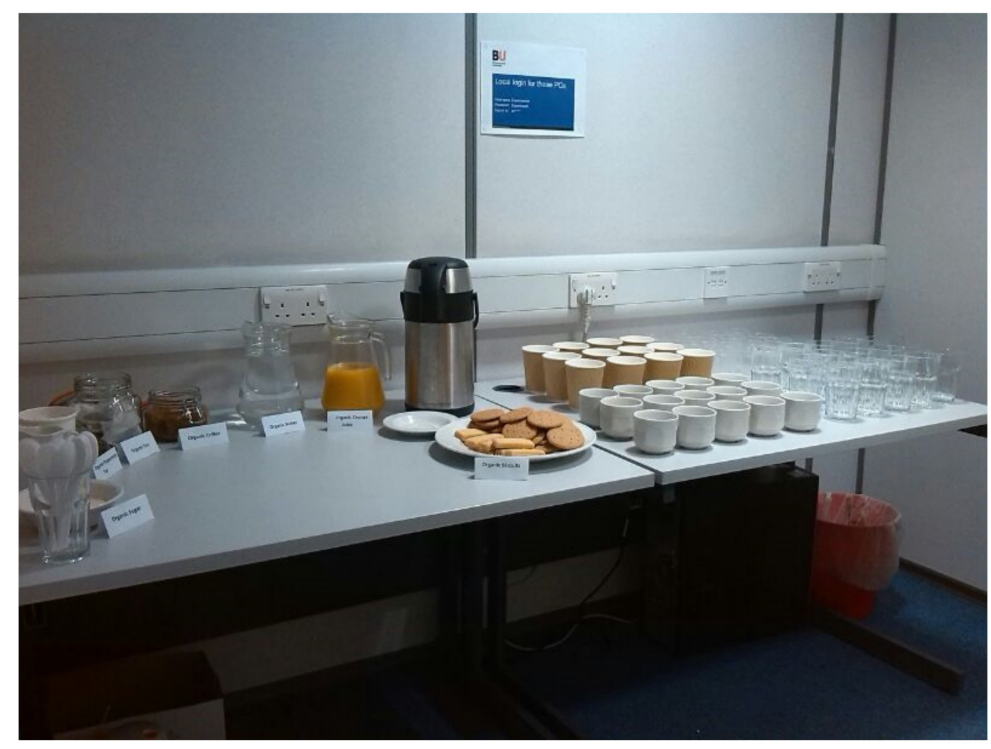

Figure A3. Left table showing organic consumables in the easier to reach position at the front of the room.

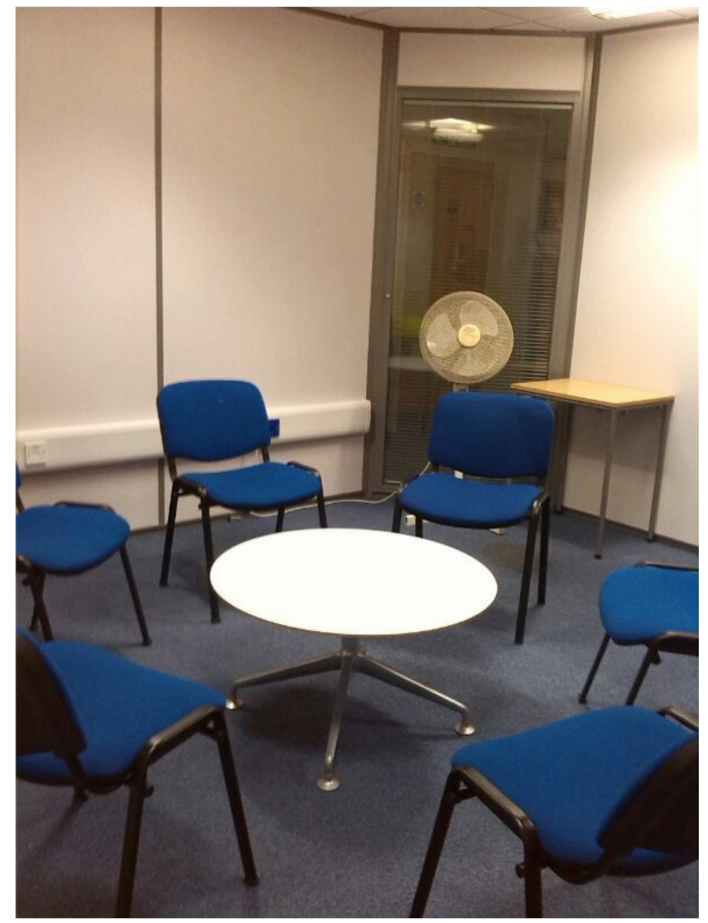

Figure A4. Feedback room.

Part 2:

Experiment activity information (Document presented to the participants)

\section{Bournemouth University, Festival of Learning Event: Psychological Experiment}

This BU Festival of Learning Event will provide you with a first-hand experience of psychological research. The text below will briefly explain what the experiment is about.

We are going to measure your grocery shopping behaviour and will ask you a bit about your social network, i.e., your friends, family and important others such as colleagues, neighbours etc. This experiment will contain written and non-written exercises. No physical or emotional harm will come to you during this experiment. However, you are 
free to withdraw your participation at any time during the experiment. The exact purpose of the study, its design and results will be explained to you after your participation.

This document contains four brief exercises. Please follow them in order. Don't look at the next page until you have completed the exercise on the page before.

The information that you provide will be treated in the strictest confidence and you will not be identified in any way, in line with the British Psychological Society's Code of Conduct. In order for the researchers to use your anonymous data in the future we would like to ask you to provide written consent.

- I confirm that I have read and understood the information about the project above.

- I understand that my participation is voluntary and that I am free to stop participating at any point while completing the study, without having to give a reason and without any consequences.

- I understand that any information recorded in the investigation will remain confidential and no information that identifies me will be made publicly available.

- I consent to taking part in this experiment which is part of the BU Festival of Learning Event.

Signed Date

The first set of questions will ask you about your current food shopping behaviour. This should be answered independently by each participant and forms the basis of the experiment.

Q1. How often do you buy any of the following.

\begin{tabular}{cccccccc}
\hline I Buy... & Never & $\begin{array}{c}\text { Almost } \\
\text { Never }\end{array}$ & Seldom & Sometimes & Often & $\begin{array}{c}\text { Almost } \\
\text { Always }\end{array}$ & Always \\
\hline Fairtrade food & $\bigcirc$ & $\bigcirc$ & $\bigcirc$ & $\bigcirc$ & $\bigcirc$ & $\bigcirc$ & $\bigcirc$ \\
$\begin{array}{c}\text { Organic food } \\
\text { Food with little }\end{array}$ & $\bigcirc$ & $\bigcirc$ & $\bigcirc$ & $\bigcirc$ & $\bigcirc$ & $\bigcirc$ & $\bigcirc$ \\
$\begin{array}{c}\text { or no packing } \\
\text { Locally sourced } \\
\text { food }\end{array}$ & $\bigcirc$ & $\bigcirc$ & $\bigcirc$ & $\bigcirc$ & $\bigcirc$ & $\bigcirc$ & $\bigcirc$ \\
\hline
\end{tabular}

Please now compare your food shopping behaviour above with that of your discussion partner. The options above describe sustainable food shopping behaviour, e.g., buying fair-trade or organic food. Everyone shows some differences and similarities in sustainable shopping. How similar or dissimilar are you to your discussion partner in your sustainable food shopping. If you live in the same household and eat or buy the food together, would you do things differently if this was not the case? Please write down some brief notes.

Q2. How regularly do you buy sustainable food products that can be described by the categories above (i.e., fair-trade, organic, little or no packaging and locally sourced food)? (revealed descriptive norms)

Similarities:

Differences:

Q3: How important do you think it is to buy sustainable food and why?

Similarities:

Differences:

The next set of questions should be answered independently again by each participant. The questions will ask some information about your food shopping behaviour and your social network, i.e., friends, family and important others.

Q4. Which sustainable food products do you intent to buy during your next shop? (this question was used as a decoy to reflect from the actual consumption data collection after the activity, hence it was not analysed). 


\begin{tabular}{|c|c|c|c|c|c|c|c|}
\hline $\begin{array}{l}\text { I Intent to } \\
\text { Buy... }\end{array}$ & $\begin{array}{c}\text { Very } \\
\text { Unlikely }\end{array}$ & Unlikely & $\begin{array}{l}\text { Somewhat } \\
\text { Unlikely }\end{array}$ & $\begin{array}{c}\text { Neither } \\
\text { Likely Nor } \\
\text { Unlikely }\end{array}$ & $\begin{array}{l}\text { Somewhat } \\
\text { Likely }\end{array}$ & Likely & $\begin{array}{c}\text { Very } \\
\text { Likely }\end{array}$ \\
\hline $\begin{array}{c}\text { Fairtrade } \\
\text { food }\end{array}$ & 0 & $\mathrm{O}$ & 0 & 0 & 0 & 0 & 0 \\
\hline Organic food & O & 0 & O & 0 & 0 & $\mathrm{O}$ & 0 \\
\hline $\begin{array}{l}\text { little or no } \\
\text { packing }\end{array}$ & 0 & 0 & 0 & 0 & 0 & 0 & 0 \\
\hline $\begin{array}{c}\text { Locally } \\
\text { sourced food }\end{array}$ & $\mathrm{O}$ & $\mathrm{O}$ & $\mathrm{O}$ & $\mathrm{O}$ & $\mathrm{O}$ & $\mathrm{O}$ & $\mathrm{O}$ \\
\hline
\end{tabular}

Q5. How large is the percentage of people that buy sustainable food products in your social network:

Please use the slider bar below to indicate the percentage of people that buy sustainable food products in your social network by marking your answer with an $\mathbf{X}$ in the appropriate position. Below are some guidelines:

$\leq 25 \%$ indicating a minority (about $1 / 4$ or less)

$\approx 50 \%$ (more or less half of the people)

$\geq 75 \%$ indicating a majority (more than $3 / 4$ of the people)

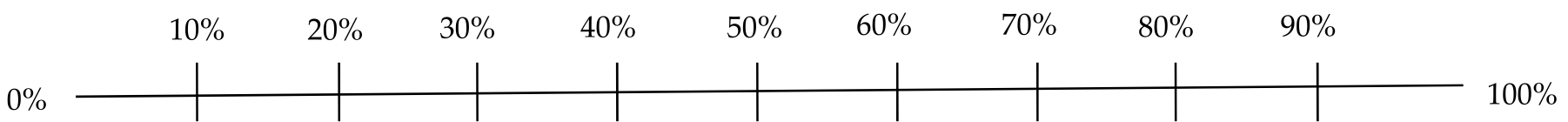

Q6. How large is your social network of friends, family and important others? Please tick one of the options below.

I count _ people in my close social network

$\circ \quad 1-5$

○ $6-10$

○ 11-15

○ $16-20$

○ $21-25$

○ $26-30$

$\bigcirc>30$

Q7. Is the person sitting next to you included in your above estimation of your network size? (If they are not a stranger to you) (to verify the relationship between network partners and strangers, not analysed)

○ Yes

○ No

Q8. How long have you known the person sitting next to you?

I I don't really know them

- Relationship lengths in years

Q9. What is your current age?

Q10. Are you:

○ Male

$\bigcirc \quad$ Female 
This is the end of the experiment. Please join the researchers for a tea/coffee and biscuit to discuss the experiment.

\section{References}

1. Schmidt, S.; Weigt, H. Interdisciplinary Energy Research and Energy Consumption: What, Why, and How? Energy Res. Soc. Sci. 2015, 10, 206-219. [CrossRef]

2. UNEP Secretariat United Nations Environment Programme (UNEP). Global Environment Outlook 5, Summary for Policy Makers; UNEP Secretariat United Nations Environment Programme (UNEP): Nairobi, Kenya, 2012.

3. Mkono, M. Eco-Anxiety and the Flight Shaming Movement: Implications for Tourism. J. Tour. Futures 2020, 6, 223-226. [CrossRef]

4. Elofsson, A.; Smedby, N.; Larsson, J.; Nässén, J. Local Governance of Greenhouse Gas Emissions from Air Travel. J. Environ. Policy Plan. 2018, 20, 578-594. [CrossRef]

5. Rucht, D.; Sommer, M. Fridays for Future. Vom Phänomen Greta Thunberg, medialer Verkürzung und geschickter Mobilisierung: Zwischenbilanz eines Höhenflugs. Int. Polit. 2019, 74, 121-125.

6. The Politics of Protest: Readings on the Black Lives Matter Movement. Available online: https://www.routledge.com/ThePolitics-of-Protest-Readings-on-the-Black-Lives-Matter-Movement/Brown-Jr-Stout/p/book/9780367635664 (accessed on 25 April 2021).

7. Diani, M. Networks and Social Movements. Wiley-Blackwell Encycl. Soc. Political Mov. 2013.

8. Krinsky, J.; Crossley, N. Social Movements and Social Networks: Introduction. Soc. Mov. Stud. 2014, 13, 1-21. [CrossRef]

9. Bandura, A. Self-Efficacy: Toward a Unifying Theory of Behavioral Change. Psychol. Rev. 1977, 84, 191-215. [CrossRef]

10. Tajfel, H.; Turner, J.C. The Social Identity Theory of intergroup behavior. In Political Psychology: Key Readings. Key Readings in Social Psychology; Jost, J.T., Sidanius, J., Eds.; Psychology Press: New York, NY, USA, 2004; pp. $276-293$.

11. Turner, J.C.; Hogg, M.A.; Oakes, P.J.; Reicher, S.D.; Wetherell, M.S. Rediscovering the Social Group: A Self-Categorization Theory; Rediscovering the Social Group: A Self-Categorization Theory; Basil Blackwell: Cambridge, MA, USA, 1987; p. 239, ISBN 978-0631-14806-7.

12. Bicchieri, C.; McNally, P. Shrieking sirens: Schemata, scripts, and social norms. How change occurs. Soc. Philos. Policy 2018, 35, 23-53. [CrossRef]

13. Sparkman, G.; Walton, G.M. Dynamic Norms Promote Sustainable Behavior, Even If It Is Counternormative. 2017. Available online: https:/ /journals.sagepub.com/doi/full/10.1177/0956797617719950?casa_token=ZeN0zw5dFssAAAAA\%3AeTqgAlf7 _q1WOTcmLVyI9eTPXJrFaR8-bLvwmNFQd8ycpcokhUUSd7-C5ZM6mZLUp6Cy53eGKAU (accessed on 25 April 2021).

14. Cialdini, R.B.; Demaine, L.J.; Sagarin, B.J.; Barrett, D.W.; Rhoads, K.; Winter, P.L. Managing Social Norms for Persuasive Impact. Soc. Influ. 2006, 1, 3-15. [CrossRef]

15. Bergquist, M.; Nilsson, A.; Schultz, W.P. A Meta-Analysis of Field-Experiments Using Social Norms to Promote pro-Environmental Behaviors. Glob. Environ. Chang. 2019, 59, 101941. [CrossRef]

16. Keizer, K.; Schulz, P.W. Social Norms and Pro-Environmental Behavior. Environmental Psychology: An Introduction; John Wiley \& Sons: Oxford, UK, 2012; pp. 153-163.

17. Smith, J.R.; Louis, W.R.; Terry, D.J.; Greenaway, K.H.; Clarke, M.R.; Cheng, X. Congruent or Conflicted? The Impact of Injunctive and Descriptive Norms on Environmental Intentions. J. Environ. Psychol. 2012, 32, 353-361. [CrossRef]

18. Determinants of CO 2 Emissions Generated by Air Travel Vary across Reasons for the Trip SpringerLink. Available online: https:/ /link.springer.com/article/10.1007/s11356-020-12219-4 (accessed on 25 April 2021).

19. Cialdini, R.B.; Trost, M.R. Social influence: Social norms, conformity and compliance. In The Handbook of Social Psychology; McGraw-Hill: New York, NY, USA, 1998; pp. 151-192.

20. Jacobson, R.P.; Mortensen, C.R.; Cialdini, R.B. A Body Obliged: The Role of Self-Regulation in Normative Social Influence. 2010; Unpublished.

21. Charry, K.; Tessitore, T. I Tweet, They Follow, You Eat: Number of Followers as Nudge on Social Media to Eat More Healthily. Soc. Sci. Med. 2021, 269, 113595. [CrossRef]

22. Furth-Matzkin, M.; Sunstein, C.R. Social Influences on Policy Preferences: Conformity and Reactance. Minn. L. Rev. 2017, 102, 1339.

23. Hallström, E.; Carlsson-Kanyama, A.; Börjesson, P. Environmental Impact of Dietary Change: A Systematic Review. J. Clean. Prod. 2015, 91, 1-11. [CrossRef]

24. Smith, P.; Bustamante, M.; Ahammad, H.; Clark, H.; Dong, H.; Elsiddig, E.A.; Haberl, H.; Tubiello, F. Agriculture, Forestry and Other Land Use (AFOLU). In Climate Change 2014: Mitigation of Climate Change. Contribution of Working Group III to the Fifth Assessment Report of the Intergovernmental Panel on Climate Change; Edenhofer, O.R., Pichs-Madruga, Y., Sokona, E., Farahani, S., Kadner, K., Seyboth, A., Adler, I., Baum, S., Brunner, P., Eickemeier, B., et al., Eds.; Cambridge University Press: Cambridge, UK; New York, NY, USA, 2014.

25. Meiselman, H.L. (Ed.) Handbook of Eating and Drinking: Interdisciplinary Perspectives; Springer International Publishing: Cham, Switzerland, 2020; ISBN 978-3-030-14503-3.

26. Pachucki, M.A.; Jacques, P.F.; Christakis, N.A. Social Network Concordance in Food Choice Among Spouses, Friends, and Siblings. Am. J. Public Health 2011, 101, 2170-2177. [CrossRef] [PubMed] 
27. Changing What We Eat: A Call for Research \& Action on Widespread Adoption of Sustainable Healthy Eating TABLE Debates. Available online: https://www.tabledebates.org/research-library/changing-what-we-eat-call-research-action-widespreadadoption-sustainable-healthy (accessed on 25 April 2021).

28. DiGuiseppi, G.T.; Meisel, M.K.; Balestrieri, S.G.; Ott, M.Q.; Clark, M.A.; Barnett, N.P. Relationships between Social Network Characteristics, Alcohol Use, and Alcohol-Related Consequences in a Large Network of First-Year College Students: How Do Peer Drinking Norms Fit In? Psychol. Addict. Behav. 2018, 32, 914. [CrossRef] [PubMed]

29. Gudzune, K.A.; Opara, O.; Martinez, J.C.; Doshi, R.S.; Levine, D.M.; Latkin, C.A.; Clark, J.M. Social Network Intervention Reduces Added Sugar Intake Among Baltimore Public Housing Residents: A Feasibility Study. Nutr. Metab. Insights 2020, 13, 1178638820909329. [CrossRef] [PubMed]

30. Arias, N.; Calvo, M.D.; Benítez-Andrades, J.A.; Álvarez, M.J.; Alonso-Cortés, B.; Benavides, C. Socioeconomic Status in Adolescents: A Study of Its Relationship with Overweight and Obesity and Influence on Social Network Configuration. Int. J. Environ. Res. Public Health 2018, 15, 2014. [CrossRef]

31. Lazaric, N.; Le Guel, F.; Belin, J.; Oltra, V.; Lavaud, S.; Douai, A. Determinants of Sustainable Consumption in France: The Importance of Social Influence and Environmental Values. J. Evol. Econ. 2020, 30, 1337-1366. [CrossRef]

32. Lucas, S.; Salladarré, F.; Brécard, D. Green Consumption and Peer Effects: Does It Work for Seafood Products? Food Policy 2018, 76, 44-55. [CrossRef]

33. Salazar, H.A.; Oerlemans, L.; van Stroe-Biezen, S. Social Influence on Sustainable Consumption: Evidence from a Behavioural Experiment. Available online: https://onlinelibrary.wiley.com/doi/full/10.1111/j.1470-6431.2012.01110.x?casa_token= jrZZVhTXuB0AAAAA\%3AajTR8hRUK-3Ilgpu5kXrd8UT17MGnCAP4ZVveIGrTVR4TVWR1ch8qDPUgncGUezk9rsfE6Buv16 2zA (accessed on 25 April 2021).

34. Robinson, E.; Thomas, J.; Aveyard, P.; Higgs, S. What Everyone Else Is Eating: A Systematic Review and Meta-Analysis of the Effect of Informational Eating Norms on Eating Behavior. J. Acad. Nutr. Diet. 2014, 114, 414-429. [CrossRef] [PubMed]

35. Scott, J. Social Network Analysis, 4th ed.; Sage Publications: London, UK, 2017.

36. Schubert, I. Understanding the Influence of Individual Behaviour and Social Networks in Sustainability Transitions; Bournemouth University: Fern Barrow, UK, 2015; p. 309.

37. De Groot, J.; Steg, L. General Beliefs and the Theory of Planned Behavior: The Role of Environmental Concerns in the TPB. J. Appl. Soc. Psychol. 2007, 37, 1817-1836. [CrossRef]

38. De Groot, J.I.; Steg, L. Mean or Green: Which Values Can Promote Stable pro-Environmental Behavior? Conserv. Lett. 2009, 2, 61-66. [CrossRef]

39. Robinson, R.; Smith, C. Psychosocial and Demographic Variables Associated with Consumer Intention to Purchase Sustainably Produced Foods as Defined by the Midwest Food Alliance. J. Nutr. Educ. Behav. 2002, 34, 316-325. [CrossRef]

40. Magnusson, M.K.; Arvola, A.; Koivisto Hursti, U.; Åberg, L.; Sjödén, P. Attitudes towards Organic Foods among Swedish Consumers. Br. Food J. 2001, 103, 209-227. [CrossRef]

41. Padel, S.; Foster, C. Exploring the Gap between Attitudes and Behaviour: Understanding Why Consumers Buy or Do Not Buy Organic Food. Br. Food J. 2005, 107, 606-625. [CrossRef]

42. Aertsens, J.; Verbeke, W.; Mondelaers, K.; Van Huylenbroeck, G. Personal Determinants of Organic Food Consumption: A Review. Br. Food J. 2009, 111, 1140-1167. [CrossRef]

43. Hoek, A.C.; Pearson, D.; James, S.W.; Lawrence, M.A.; Friel, S. Healthy and Environmentally Sustainable Food Choices: Consumer Responses to Point-of-Purchase Actions. Food Qual. Prefer. 2017, 58, 94-106. [CrossRef]

44. Kashima, Y.; Wilson, S.; Lusher, D.; Pearson, L.J.; Pearson, C. The Acquisition of Perceived Descriptive Norms as Social Category Learning in Social Networks. Soc. Netw. 2013, 35, 711-719. [CrossRef]

45. Latkin, C.A.; Forman, V.; Knowlton, A.; Sherman, S. Norms, Social Networks, and HIV-Related Risk Behaviors among Urban Disadvantaged Drug Users. Soc. Sci. Med. 2003, 56, 465-476. [CrossRef] 